\title{
The Making of a Competent Oocyte - A Review of Oocyte Development and Its Regulation
}

\author{
Hammed A. Tukur ${ }^{1}$, Riyadh S. Aljumaah ${ }^{1}$, Ayman Abdel-Aziz Swelum ${ }^{1,3}$, Abdullah N. Alowaimer ${ }^{1}$ \\ and Islam M. Saadeldin ${ }^{1,2, *}$ \\ ${ }^{1}$ Department of Animal Production, College of Food and Agricultural Sciences, King Saud University, Riyadh 11451, \\ Kingdom of Saudi Arabia \\ ${ }^{2}$ Department of Physiology, Faculty of Veterinary Medicine, Zagazig University, Zagazig 44519, Egypt \\ ${ }^{3}$ Department of Theriogenology, Faculty of Veterinary Medicine, Zagazig University, Zagazig 44519, Egypt
}

Received January 20, 2020

Revised February 24, 2020

Accepted March 12, 2020

\section{*Correspondence \\ Islam M. Saadeldin \\ E-mail: isaadeldin@ksu.edu.sa}

ORCID

https://orcid.org/0000-0002-7633-730X

\begin{abstract}
Assisted reproductive technologies (ART) merely depend on improving the oocyte maturation and their developmental competence to produce good quality embryos. Oocyte maturation passes through long and complex molecular steps starts from the early embryonic life and ends with sperm fertilization. Oocyte developmental competence can be attained by improving the nuclear and cytoplasmic mechanisms together with some epigenetic maturation. In this review, we highlight the cornerstones of oocyte maturation on both nuclear and cytoplasmic levels. Interfering or supporting these molecular mechanisms would help in the development of novel regulating agents for reproductive performance of humans and livestock species.
\end{abstract}

Keywords: cytoskeleton, development, maturation, meiotic arrest, oocyte

\section{INTRODUCTION}

In 1651, William Harvey strongly proposed that the life of animals begins from the ovum (a mature oocyte). This proposition was generally accepted to be true even though Harvey provided no evidence for his claim. It was in 1826 that Karl Ernst von Baer identified and described the mammalian oocytes in his study on bitch ovary (von Baer and O'Malley, 1956). After Karl's observation was confirmed by several scientists, exhaustive research was done which further described oocyte metamorphosis and early embryonic development. From that time and up till the present, the oocyte has become the focus of researchers in understanding issues of reproduction, fertility enhancement, early embryogenesis, breed conservation (especially endangered species and animal of high genetic merit), and other aspects of assisted reproduction.

In all living things, survival and conservation of species is only possible if reproduction is successful. Assisted Reproductive Technologies (ARTs) have come to the rescue of several reproductive challenges in human and livestock. ARTs including embryo transfer and in vitro embryo production are being applied to maximize the productivity and genetic potential of livestock, preserve endangered species and livestock of high genetic merit (Comizzoli et al., 2018; Herrick, 2019). Also, using oocyte for somatic genome reprogramming and cloning have opened the door for regenerative medicine in livestock and human (Hyttel et al., 2019).

In spite of these great achievements and promising future, ARTs is still inefficient in its overall application (Conti and Franciosi, 2018). The oocyte has been noted to play a 
central role in the success of reproduction, and it is also, a major block to the advancement of ARTs (Conti and Franciosi, 2018). In embryo production, oocyte health is the major determinant of the success of sperm-egg interaction and early embryogenesis. In dairy cattle, even when there was huge success following genomic selection for milk traits, unintended loss of embryo and reproductive failures were reported (Pryce et al., 2004; Matoba et al., 2012). Studies have shown that oocyte health of heavy lactating dairy cattle is negatively affected contributing to the associated reproductive failure in the dairy cattle industry (Poirier et al., 2020). Also, oocyte reprogramming potential is crucial to the success of regenerative medicine (Zakrzewski et al., 2019). Hence, deeper understanding and research on oocyte development and its regulation is essential.

This review explores and summarizes the current understanding on oocyte maturation. An account of the events leading to oocyte formation from the fetal ovary to its readiness to accept spermatozoon and become fertilized is covered.

\section{THE OVARY AND FOLLICULOGENESIS}

The mammalian ovary has two primary functions; production of female germ cells (oocytes) for successful fertilization and subsequent embryo production, and the generation of hormones including steroids (estrogen and progesterone), and peptide growth factors all of which serve to control estrous cycle and oocyte production (Edson et al., 2009; Jones and Shikanov, 2019). With these two major functions, the mammalian ovary controls and regulates the development and physiology of females. The ovary therefore is part of both the reproductive system and the endocrine system (Hummitzsch et al., 2013).

The ovary is made up of several cell types, but the main cells that are involved in ovarian function and oocyte production are the theca and granulosa cells (Richards et al., 2018; Moncrieff et al., 2019). Both cells work together to make up the physical structure of ovarian follicles and are essential in steroidogenesis (Richards et al., 2018; Moncrieff et al., 2019). The interaction between the two cells is the foundation for the two-cell theory. Theca cells produce androgens which are converted into estrogens in the granulosa cell (Young and McNeilly, 2010; Forde et al., 2011).
The embryonic precursors of both the male and female gametes are the primordial germ cells (PGCs) - the undifferentiated cells that have the potential of developing into spermatozoa or oocytes (Edson et al., 2009). The fate of the germ cells is known during earliest stage of development stage, during cleavage or in the epiblast (Britt, 2008; Marlow, 2015; Downs, 2018). The germ cells then undergo two developmental stages. In the first embryonic stage, primordial germ cells exit the yolk sack through the embryonic hindgut to settle in the gonadal ridge and proliferate mitotically (Takagi et al., 1997; Hummitzsch et al., 2019). In the ovine, the PGC (now referred to as oogonia) are present during day 23 of gestation (McNatty et al., 2019). Then they migrate and settle at the gonadal ridge to multiply and undergo a final round of DNA replication and meiotic crossing over. This marks the beginning of meiosis I. At this stage, the oogonia have developed into the primary oocytes. They are then arrested at the diplotene stage of prophase I until the reproductive age when estrous begins. A single diplotene-arrested oocyte is surrounded by flattened pre-granulosa cells to form the primordial follicle, a functional unit of the ovary (Jones and Shikanov, 2019; Pan and Li, 2019). The pregranulosa cells, at this stage can synthesize some steroids with which the oocyte is nurtured (Jones and Shikanov, 2019; Moncrieff et al., 2019). It is important to note that the formation of oocytes occur simultaneously with folliculogenesis. Folliculogenesis starts with the recruitment or activation of a primordial follicle (in response to surge of pituitary leutinizing hormone) into a pool of growing population of follicles. And it ends with ovulation, the release of mature oocyte or death by atresia.

The formation of primordial follicle marks the beginning of the process of oogenesis, the production of oocytes. After activation, they are transformed into primary follicles. This activation is characterized by the cuboidal appearance (previously flattened) of the surrounding granulosa cells (Paulini et al., 2014; Jones and Shikanov, 2019). The granulosa cells proliferate and give rise to several layers to surround the oocyte. Oocyte growth is simultaneously stimulated and a zonal pellucida is formed between the oocytes and granulosa cells. The follicle at this stage is now a secondary or preantral follicle (Paulini et al., 2014). By continued proliferation and differentiation of cells surrounding the oocytes into cumulus and theca cells, and formation of antrum, a fluid-filled cavity, 
a tertiary or antral follicle is formed (Paulini et al., 2014).

\section{OOCYTE MATURATION, MEIOSIS AND MEIOTIC ARREST}

Earlier researchers including described oocyte maturation or meiotic maturation as the many uniquely coordinated and complex events that prepare the oocyte to receive the sperm and become fertilized, and the early stages of embryogenesis (Eppig, 1996). In other words, oocyte maturation leads to the generation of competent fertilizable oocytes (Fan and Sun, 2019; Pan and Li, 2019). The process of oocyte maturation comprises essential developmental events. Remarkably, these include nuclear maturation, cytoplasmic maturation (Eppig, 1996) and epigenetic maturation (Fan and Sun, 2019; Viveiros and De La Fuente, 2019).

Nuclear maturation is the progression of oocyte from the stage of intact nucleus (germinal vesicle, GV stage) in prophase I to metaphase II arrest. The process eventually leads to reduction of chromosome to haploid. Nuclear maturation includes acquisition of meiotic competence, meiotic resumption and completion of the meiosis I as well as the maintenance of metaphase-II arrest. Meiotic competence is attained when the growing oocyte that is arrested at prophase I is able to reinitiate meiosis (Sorensen and Wassarman, 1976). In the fetal ovary, during the early-follicular growth period, the oocyte increase in size and volume and the granulosa cells add more layers to form pre-antral follicle. In addition, the thecal cell appears at the basement membrane surrounding the granulosa cells. Although oocyte within the pre-antra follicle cannot resume meiosis (Conti et al., 2012), the events during this stage are necessary for successful oocyte growth (Sorensen and Wassarman, 1976). The Production of essential proteins and molecules to support further events of oocyte maturation, meiotic resumption, fertilization and pre-implantation embryo occur during this period.

Oocyte meiosis seizes when the intra oocyte concentration of cyclic adenosine 3,5-monophosphate (cAMP) is high. The surrounding granulosa cells regulate oocyte cAMP level and meiotic resumption (Viveiros and De La Fuente, 2019). In the antral follicle, the mural granulosa cells line the inside of the follicle wall while cumulus cells surround the oocyte. The mural granulosa cells produce natriuretic peptide precursor C (NPPC) which promotes cyclic guanosine monophosphate (cGMP) synthesis. NPPC binds to its receptor guanylyl cyclase-linked natriuretic peptide receptor 2 (NPR2) in the neighbouring cumulus cells. Then cGMP enters into the oocyte via network of connexin gap junction (Saadeldin et al., 2015; Campen et al., 2018) and inhibits the cAMP-hydrolyzing effect of phosphodiesterase 3A (PDE3A) enzymes (Egbert et al., 2014; Fan and Sun, 2019; Yang et al., 2019) (Fig. 1). This raises intra oocyte cAMP level. High cAMP activates protein kinase A (PKA) which in turns phosphorylates the enzyme, WEE1B kinase and prevents CDC25B phosphatase causing the inactivation of cyclin-dependent kinase 1 (CDK1), a family of Maturation-Promoting Factor (MPF) (Pirino et al., 2009; Kim et al., 2015). The joint effects of these enzymes lead to the continued inhibition of MPF action and hence, meiotic arrest is sustained. The role of cAMP and cGMP, in this process has been elucidated in a number of studies (Gilchrist et al., 2016; Li et al., 2018).

\section{OOCYTE MEIOTIC RESUMPTION}

In late antral stage, the oocytes have become fully grown and competent to resume and continue meiosis I (Solc et al., 2010). Pituitary luteinizing hormone (LH) is the major signal for oocyte meiotic resumption; LH receptors in outer granulosa cells receive signals from LH causing disruption of gap junction communication between the oocytes and surrounding somatic cells in the follicle. This is followed by dephosphorylation of NPPC and reduction of its binding affinity leading to marked reduction in NPPC/ NPR2 level, and inactivation of NPR2 and a rapid reduction of cGMP supply to the oocyte (Egbert et al., 2014). Activation of phosphodiesterase (PDE3A) causes cAMP hydrolysis and therefore, PKA becomes inactive, losing the ability to phosphorylate WEE1B kinase and inactivate CDC25B. Therefore, CDK1 becomes dephosphorylated and catalytically ready to initiate meiotic resumption and thus GVBD. Nuclear maturation starts with GVBD. GVBD is characterized by gradual chromatin decondensation, nucleolus disappearance and nuclear membrane disintegration.

After oocyte nucleus (germinal vesicle) breaks down, the chromatin rapidly condenses to form chromosomes, and a bipolar microtubule spindle is formed. In meiosis I, the spindle migrates to the oocyte surface and half of 


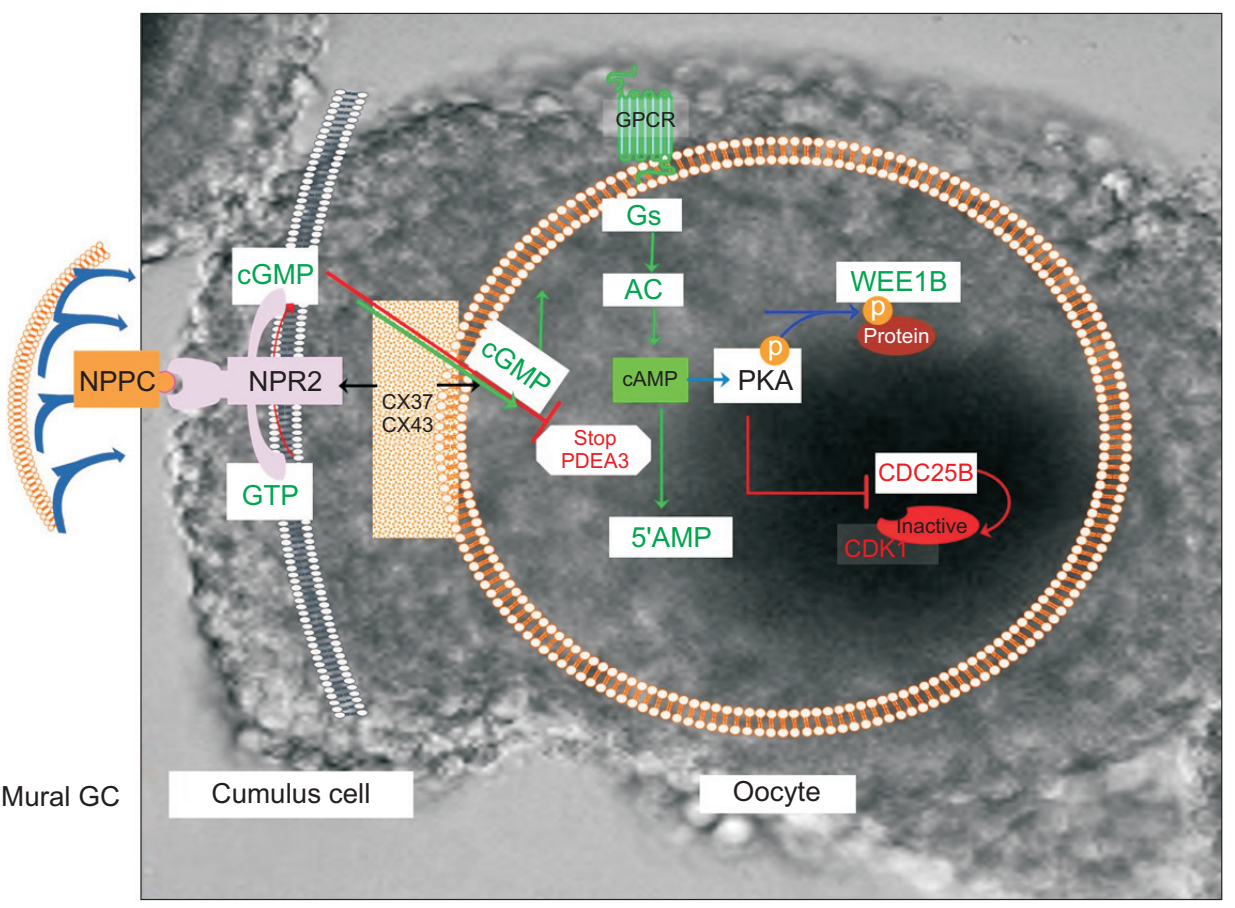

Fig. 1. Diagrammatic description of the molecular events leading to oocyte meiotic arrest at prophase I. The processes leading to oocyte arrest in prophase begin when natriuretic peptide precursor C (NPPC) from the mural granulosa binds to its receptor, guanylyl cyclase-linked natriuretic peptide receptor 2 (NPR2) on the cumulus cell promoting cyclic guanosine monophosphate (cGMP) synthesis. cGMP enters into the oocyte via network of connexin gap junction to stop phosphodiesterase 3A (PDE3A) enzymes from hydrolyzing CAMP. As more and more CAMP is produced, protein kinase $A$ (PKA) becomes active to phosphorylates WEE1B kinase and prevents CDC25B phosphatase. Inactivation of CDC25B causes the inactivation of cyclin-dependent kinase 1 (CDK1) and thus, prophase arrest is sustained. Modified following (Fan and Sun, 2019; Pan and Li, 2019). the homologous chromosomes segregates into a small unit (first polar body) which is extruded (Maddox et al., 2012; Roeles and Tsiavaliaris, 2019; Viveiros and De La Fuente, 2019). This marks the completion of first meiosis. The remaining chromosomes are captured by a second meiotic spindle and again, the oocyte meiosis seized a second time at metaphase II until activation or fertilization by sperm. Oocyte fertilization or activation initiates second meiotic division and it entails the segregation of sister chromatids, which becomes reduced after one set is extruded into second polar body (Roeles and Tsiavaliaris, 2019; Viveiros and De La Fuente, 2019). In most mammalian species (except dogs and foxes) meiotic maturation ends at the MII stage, just before the time of ovulation.

Pioneering investigation on MII arrest was first observed by Masui and Markert (1971) in MII of Xenopus oocytes. They discovered that a cell cycle arresting state, termed "cytostatic factor" (CSF) is indispensable for metaphase II arrest. Further studies on CSF showed that CSF works to balance CDK1 activity.

\section{CYTOPLASMIC MATURATION}

Oocyte cytoplasmic maturation is a non-chromatin based maturation which prepares the oocyte for sperm reception, activation and pre-implantation development.
It is the gross structural changes in the oocyte which include rearrangement of cellular organelles (mitochondria, ribosome, endoplasmic reticulum, cortical granules), modulation of energy level, and accumulation of mRNA, protein and substrates to support fertilization and preembryonic development before activation of the embryonic genome (Watson, 2007; Mao et al., 2014).

Successful oocyte meiosis does not only require proper chromosomal segregation (nuclear maturation), proper and distribution of cellular organelles (cytoplasmic maturation) is indispensable (Mao et al., 2014; Reader et al., 2017). Nuclear and cytoplasmic maturation are two different processes but they occur simultaneously and are both connected and dependent on each other. The events during oocyte cytoplasmic maturation contribute to the successful completion of oocyte nuclear maturation, its ability to become fertilized, and support early embryonic development.

Ferreira et al. (2009) and Fan and Sun (2019) classified oocyte cytoplasmic maturation into phases: cytoplasmic organelle maturation and distribution, cytoskeleton dynamics and oocyte cytoplasmic molecular maturation.

The mitochondrial, ribosome, endoplasmic reticulum, cortical granules and Golgi complex have been recognized to play significant roles in cytoplasmic maturation (Oh et al., 2015; Elahi et al., 2017). The number (of mitochon- 
dria), distribution and activities of these organelles have profound effect on oocyte and embryo development (Cotterill et al., 2013; Harvey, 2019). The mitochondria ensure oocyte energy metabolism. They provide the energy (ATP) needed for germinal vesicle breakdown, spindle organization and chromosomes segregation during oocyte nuclear maturation (Mao et al., 2014; Babayev and Seli, 2015; Fan and Sun, 2019). As expected, the ATP generated in the mitochondria is required for the synthesis of proteins that support the entire maturation process and early embryo development. Mitochondria are dynamic in their distribution, they respond to oocyte energy need and hence their localization in areas of high-energy need during different stages of maturation. Immature oocytes from early antral follicles have their mitochondria mainly in the cortex, while in mature GV oocytes mitochondria localized in the peripheral cytoplasm and around the GV.

Endoplasmic reticulum (ER) reorganization occurs during cytoplasmic maturation. The ER is the main reservoir of calcium ion which is needed for resumption and completion of second meiotic division, prevention of polyspermy and recruitment of maternal mRNAs necessary for embryonic genome activation (Ajduk et al., 2008). Golgi apparatus is needed in intracellular transport of protein. They are spread all over the ooplasm but are more localized in the interior region than in the cortex. However, as oocyte maturation progresses, Golgi apparatus, ribosome, and lysosomes become less and are very rare in fully mature oocytes (Fan and Sun, 2019).

The cytoskeleton, being both rigid and stable, plays a crucial role in oocyte maturation. It rigidity helps to maintain oocyte structural integrity and organelle motility, support cytoplasmic transport, positioning and redistribution of organelles, and resist mechanical stress. Also, the cytoskeleton is capable of adjustment, disassembling and reassembling to meet cell requirements at different stages for morphological change, migration, chromosome movement and asymmetric division (Sun and Schatten, 2006; Robert et al., 2016; Fan and Sun, 2019). The three main filaments that make up the cytoskeleton are microfilaments (actin filaments), microtubules, and intermediate filaments.

\section{OOCYTE CYTOPLASMIC MOLECULAR MATURATION}

Oocyte maturation depends on the translational regulation of stored maternal mRNA. Molecular events in oocyte cytoplasm during maturation include mRNA storage, regulation of the abundantly stored maternal mRNA, translational activation, transcription, and protein synthesis (Saadeldin et al., 2012; Reyes and Ross, 2016). The growing oocyte is translationally and transcriptionally inactive - due to chromatin condensation (De La Fuente et al., 2004). As a result, the complex process of gene expression regulation during oocyte maturation is only controlled at the level of stored maternal mRNA, proteome stabilization and translation (Tetkova et al., 2019). The post-transcriptional regulation of stored maternal mRNAs (in oocyte cytoplasm) is crucial for successful completion of oocyte maturation, acquisition of competency, oocyteto-embryo transition and early embryogenesis (Wang et al., 2013; Reyes and Ross, 2016; Tetkova et al., 2019).

The temporal translation of some mRNAs is the only source for the synthesis of protein which supports oocyte meiotic maturation at particular stage (and early embryo). Hence, understanding the mechanism of transcript regulation is important. Temporally translated transcript have play essential roles in spindle assembly, maintenance of metaphase II arrest, and mRNA clearance (Sha et al., 2017). Abundance of Ank2.3 mRNA was found in prophase arrested mouse oocyte nucleus (Tetkova et al., 2019). After GVBD, Ank2.3 transcript was localized in newly forming spindle where they are translated. This suggests that localization of mRNA could also be a prerequisite for their translation (Terenzio et al., 2018). Importantly, error in mRNA translation at this level impairs oocyte cytokinesis (Tetkova et al., 2019).

Cytoplasmic polyadenylation (CP) - addition of multiple adenosine monophosphate poly(A) tail to mRNA- has been identified as the main regulator of mRNA translation in the oocyte (Brook and Gray, 2012; Cui et al., 2013). Polyadenylation enhances transcript stability, protects mRNA from degradation, enhances translational efficiency by allows for rapid protein synthesis when transcription is quiescent (Brook and Gray, 2012). This offers an effective approach for regulating gene expression by promoting spatio-temporal translation of specific transcripts at different (specific) stages of oocyte maturation 
and location within the oocyte (Cui et al., 2013).

Cytoplasmic polyadenylation activates mRNA translation while deadenylation promotes translational repression (Eichhorn et al., 2016). Studies on both mouse and frog oocytes have shown that the deadenylation and loop formation between mRNA termini partly result in translational repression. As a result, the interaction between translation initiation factor and transcript degradation is blocked and the transcript therefore can be stored for long. Polyadenylation of stored maternal mRNAs in the oocyte is facilitated by a 3'UTR cytoplasmic polyadenylation element (CPE, UUUUAU) which binds to the transacting CPE-binding proteins CPEB (Piqué et al., 2008). Both CPE and CPEB must be present to mediate polyadenylation and polyadenylation-dependent translation of the mos and cyclin B transcripts during Xenopus oocyte maturation (Ivshina et al., 2014; Sheets et al., 2017). Importantly, CP and CP- associated elements have been shown to be indispensable for oocyte meiosis and blocking their process completely prevents completion of oocyte meiosis and oogenesis, which is a generation of new individual (Kuge and Inoue, 1992).

\section{EPIGENETIC MATURATION OF OOCYTES}

Apart from CP, epigenetic regulation of oocyte gene expression is also crucial for oogenesis and subsequent embryo development (Branco et al., 2016). A body of evidences have shown that oocyte epigenetic maturation is required for transcription regulation, establishment of maternal DNA methylation patterns, nuclear arrangement, maintenance of chromosome stability, and activation of zygote genome after fertilization (Hanna et al., 2018; Xu et al., 2019). Oocyte and embryo health will be greatly impaired if the required genes are not accurately expressed during the different stages of oocyte development (Gahurova et al., 2017). A lot of epigenetic reprogramming occur during oocyte development. In fact epigenetic reprogramming in oocyte occur throughout maturation period (Franco et al., 2013).

It is thought that epigenetic reprogramming largely contributes to the ability of the oocyte to store genetic information over a long time and ensure their accurate and safe transfer to next generation. Major epigenetic modifications that occur during oocyte maturation include transcription, chromosome stability and maternal-specific DNA methylation, histone and chromatin modification (Stewart et al., 2015; Hanna et al., 2018).

Just as observed in other human and mice, DNA methylation and histone modification control transcription in bovine, porcine and sheep oocytes and embryo (Tang et al., 2007; Racedo et al., 2009; Stelzer et al., 2015). DNA methylation involves the binding of an extra methyl group to cytosine. This change is made possible by the activity of DNA methyl transferase proteins (DNMT). The main region where DNA methylation occur is the cytosine-guanine dinucleotides $(\mathrm{CpG})$ islands. Although previous study in mice showed that oocyte can grow successfully without

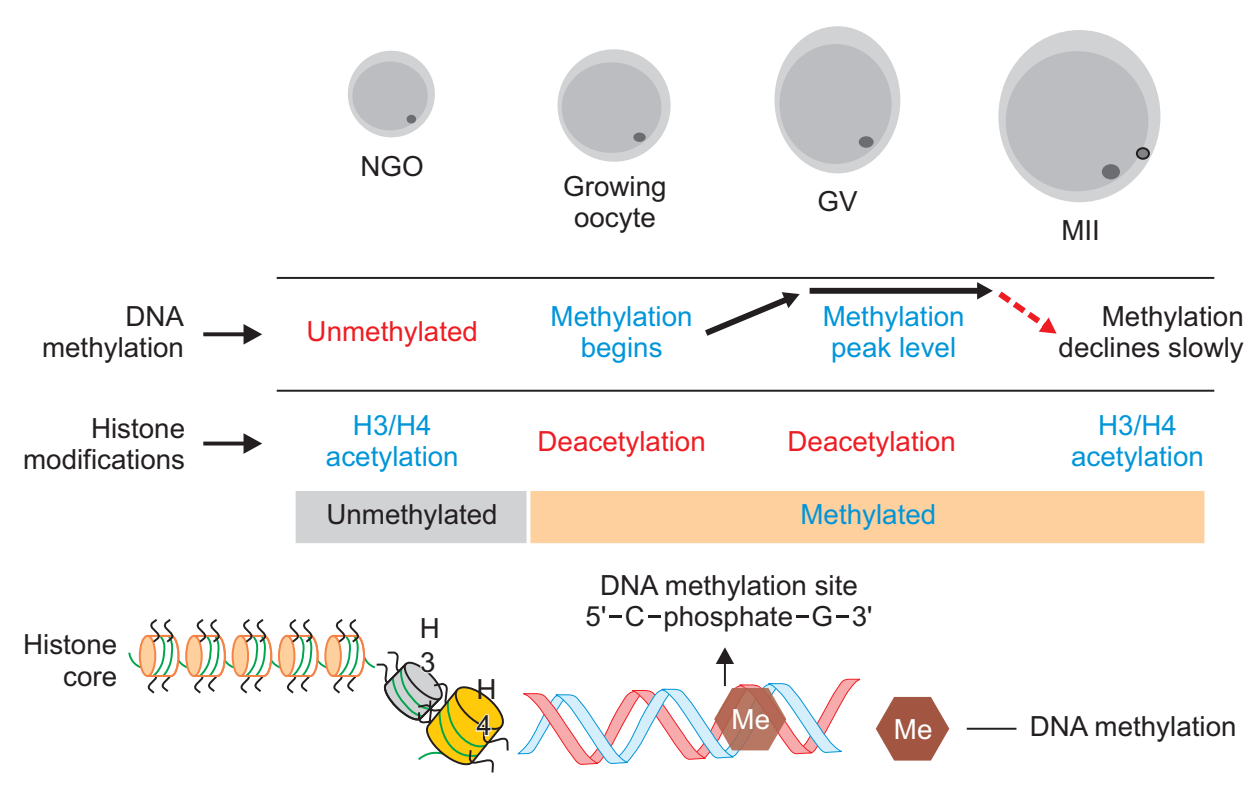

Fig. 2. Diagrammatic description of epigenetic events during oocyte maturation. Non growing oocyte (NGO) has unmethylated DNA and histone in bovine oocyte. Histone lysines $\mathrm{H} 3$ and $\mathrm{H} 4$ are acetylated at this stage. DNA methylation is initiated in bovine growing oocytes while histone changes include deacetylation until the MII stage. At germinal vesicle stage (GV), DNA methylation reaches peak. In addition, histone is methylated at the GV stage in bovine oocyte. At metaphase 2 (MII), oocyte shows decline in DNA methylation while histones proteins are acetylated. This developed and modified according to (Sendžikaite and Kelsey, 2019; Wang et al., 2006). 
DNA methylation, embryo generated from such oocyte do not survive due to abnormal transcription (Stewart et al., 2016). In oocyte, methylation of DNA begins when oocyte starts to grow. It increases gradually with oocyte size until a peak is reached at the GV stage and then a gradual decline at MII (Fig. 2). Hyper methylation of $\mathrm{CpG}$ islands was observed in bovine cumulus cell (Franco et al., 2013).

Modification of histone proteins is another important epigenetic event during oocyte maturation and embryo development. Acetylation of histone lysines $(\mathrm{K})$ in histone $\mathrm{H} 4$ (K5, K8, K12, K16) and K9, K14 in histone H3 influence oocyte chromatin organization and remodeling, and chromosome functions (Endo et al., 2005; Franciosi et al., 2012). Studies in bovine (Racedo et al., 2009) and pig (Endo et al., 2005; Wang et al., 2006) oocytes revealed that histone $\mathrm{H} 4$ acetylation at highly conserved lysine residues and the activation of histone deacetylase, which inhibit acetylation during oocytes meiosis, are necessary for correct segregation of chromosomes. Results of Jeseta et al. (2008) on pig oocyte suggested that the inhibition of histone deacetylase could improve oocyte meiotic maturation but not oocyte's ability to developed into embryo after activation. On the other hand, Jin et al. (2014) showed that oocyte experienced delayed meiotic maturation without a compromised quality following histone deacetylase inhibition. While recent report by Taweechaipaisankul et al. (2019) showed that deactylase inhibition improves embryo developmental competence. The stage and time of histone modification differs across livestock species (Gu et al., 2010). Fig. 2 shows the histone modification with regards to stage of maturation of bovine oocyte.

It is important to note that epigenetic modifications only affects the pattern of gene expression without changing the DNA sequence.

\section{CONCLUSION}

It has long been established and generally accepted that the generation of new individuals in sexually reproducing mammals largely depends on the oocyte, given its centrality in the success of reproduction. Successful transition from oocyte to embryo and from embryo to a new individual is influenced by the complex and uniquely orchestrated series of events during oocyte maturation such as nuclear and cytoplasmic maturation, meiotic resumption, and epigenetic changes in the oocytes. Although numerous research on oocyte maturation have been done and still ongoing, and their application has yielded positive but low success in ARTs, several aspects remain unclear. Hence, more research that will unveil more about the mechanisms regulating oocyte maturation, acquiring the developmental competence for fertilization and transition from gamete to embryo is worthwhile. This will lead to a more efficient ARTs intervention in animal breeding, fertility enhancement, regenerative medicine, and preservation of genetic resources of endangered species.

\section{CONFLICTS OF INTEREST}

No potential conflict of interest relevant to this article was reported.

\section{ACKNOWLEDGEMENTS}

The authors extend their appreciation to the Deanship of Scientific Research for funding H.A.T.

\section{AUTHOR CONTRIBUTIONS}

Conceptualization, H.A.T., and I.M.S; writing-original draft preparation, H.A.T., R.S.A., A.A.S., A.N.A., I.M.S.; writing-review and editing, H.A.T., R.S.A., A.A.S., A.N.A., I.M.S.; supervision, R.S.A. and I.M.S. All authors have read and agreed to the published version of the manuscript.

\section{AUTHOR'S POSITION AND ORCID NO.}

HA Tukur, MS Student, https://orcid.org/0000-0002-8708-6817

RS Aljumaah, Professor, https://orcid.org/0000-0002-5677-8095

AA Swelum, Associate Professor, https://orcid.org/0000-0003-3247-5898

AN Alowaimer, Professor, https://orcid.org/0000-0003-4646-6124

IM Saadeldin, Associate Professor, https://orcid.org/0000-0002-7633-730X

\section{REFERENCES}

Ajduk A, Małagocki A, Maleszewski M. 2008. Cytoplasmic ma- 
turation of mammalian oocytes: development of a mechanism responsible for sperm-induced $\mathrm{Ca} 2+$ oscillations. $\mathrm{Re}$ prod. Biol. 8:3-22.

Babayev E and Seli E. 2015. Oocyte mitochondrial function and reproduction. Curr. Opin. Obstet. Gynecol. 27:175-181.

Branco MR, King M, Perez-Garcia V, Bogutz AB, Caley M, Fineberg E, Lefebvre L, Cook SJ, Dean W, Hemberger M, Reik W. 2016. Maternal DNA methylation regulates early trophoblast development. Dev. Cell 36:152-163.

Britt JH. 2008. Oocyte development in cattle: physiological and genetic aspects. R. Bras. Zootec. 37:110-115.

Brook M and Gray NK. 2012. The role of mammalian poly(A)binding proteins in co-ordinating mRNA turnover. Biochem. Soc. Trans. 40:856-864.

Campen KA, Abbott CR, Rispoli LA, Payton RR, Saxton AM, Edwards JL. 2018. Heat stress impairs gap junction communication and cumulus function of bovine oocytes. J. Reprod. Dev. 64:385-392.

Comizzoli P, Paulson EE, McGinnis LK. 2018. The mutual benefits of research in wild animal species and human-assisted reproduction. J. Assist. Reprod. Genet. 35:551-560.

Conti M and Franciosi F. 2018. Acquisition of oocyte competence to develop as an embryo: integrated nuclear and cytoplasmic events. Hum. Reprod. Update 24:245-266.

Conti M, Hsieh M, Zamah AM, Oh JS. 2012. Novel signaling mechanisms in the ovary during oocyte maturation and ovulation. Mol. Cell. Endocrinol. 356:65-73.

Cotterill M, Harris SE, Collado Fernandez E, Lu J, Huntriss JD, Campbell BK, Picton HM. 2013. The activity and copy number of mitochondrial DNA in ovine oocytes throughout oogenesis in vivo and during oocyte maturation in vitro. Mol. Hum. Reprod. 19:444-450.

Cui J, Sartain CV, Pleiss JA, Wolfner MF. 2013. Cytoplasmic polyadenylation is a major mRNA regulator during oogenesis and egg activation in Drosophila. Dev. Biol. 383:121-131.

De La Fuente R, Viveiros MM, Burns KH, Adashi EY, Matzuk MM, Eppig JJ. 2004. Major chromatin remodeling in the germinal vesicle (GV) of mammalian oocytes is dispensable for global transcriptional silencing but required for centromeric heterochromatin function. Dev. Biol. 275:447-458.

Downs KM. 2018. Extragonadal primordial germ cells or placental progenitor cells? Reprod. Biomed. Online 36:6-11.

Edson MA, Nagaraja AK, Matzuk MM. 2009. The mammalian ovary from genesis to revelation. Endocr. Rev. 30:624-712.

Egbert JR, Shuhaibar LC, Edmund AB, Van Helden DA, Robinson JW, Uliasz TF, Baena V, Geerts A, Wunder F, Potter LR, Jaffe LA. 2014. Dephosphorylation and inactivation of NPR2 guanylyl cyclase in granulosa cells contributes to the LH-induced decrease in cGMP that causes resumption of meiosis in rat oocytes. Development 141:3594-3604.

Eichhorn SW, Subtelny AO, Kronja I, Kwasnieski JC, Orr-Weaver TL, Bartel DP. 2016. mRNA poly(A)-tail changes specified by deadenylation broadly reshape translation in Drosophila oocytes and early embryos. Elife 5:e16955.

Elahi F, Shin H, Lee J, Lee E. 2017. Endoplasmic stress inhibi- tion during oocyte maturation improves preimplantation development of cloned pig embryos. J. Emb. Trans. 32:287295.

Endo T, Naito K, Aoki F, Kume S, Tojo H. 2005. Changes in histone modifications during in vitro maturation of porcine oocytes. Mol. Reprod. Dev. 71:123-128.

Eppig JJ. 1996. Coordination of nuclear and cytoplasmic oocyte maturation in eutherian mammals. Reprod. Fertil. Dev. 8: 485-489.

Fan HY and Sun QY. 2019. Oocyte Meiotic Maturation. In: Leung PCK and Adashi EY (Eds.), The Ovary. Academic Press, London, pp. 181-203.

Ferreira EM, Vireque AA, Adona PR, Meirelles FV, Ferriani RA, Navarro PA. 2009. Cytoplasmic maturation of bovine oocytes: structural and biochemical modifications and acquisition of developmental competence. Theriogenology 71: 836-848.

Forde N, Beltman ME, Lonergan P, Diskin M, Roche JF, Crowe MA. 2011. Oestrous cycles in Bos taurus cattle. Anim. Reprod. Sci. 124:163-169.

Franciosi F, Lodde V, Goudet G, Duchamp G, Deleuze S, Douet C, Tessaro I, Luciano AM. 2012. Changes in histone H4 acetylation during in vivo versus in vitro maturation of equine oocytes. Mol. Hum. Reprod. 18:243-252.

Franco MM, Fagundes NS, Michalczechen-Lacerda VA, Caixeta ES, de Castro Rodrigues F, Machado GM, Ferreira AR, Dode MA. 2013. Characterisation of the methylation pattern in the intragenic $\mathrm{CpG}$ island of the IGF2 gene in Bos taurus indicus cumulus cells during in vitro maturation. J. Assist. Reprod. Genet. 31:115-120.

Gahurova L, Tomizawa SI, Smallwood SA, Stewart-Morgan KR, Saadeh H, Kim J, Andrews SR, Chen T, Kelsey G. 2017. Transcription and chromatin determinants of de novo DNA methylation timing in oocytes. Epigenetics Chromatin 10:25.

Gilchrist RB, Luciano AM, Richani D, Zeng HT, Wang X, Vos MD, Sugimura S, Smitz J, Richard FJ, Thompson JG. 2016. Oocyte maturation and quality: role of cyclic nucleotides. Reproduction 152:R143-R157.

Gu L, Wang Q, Sun QY. 2010. Histone modifications during mammalian oocyte maturation: dynamics, regulation and functions. Cell Cycle 9:1942-1950.

Hanna CW, Demond H, Kelsey G. 2018. Epigenetic regulation in development: is the mouse a good model for the human? Hum. Reprod. Update 24:556-576.

Harvey AJ. 2019. Mitochondria in early development: linking the microenvironment, metabolism and the epigenome. Reproduction 157:R159-R179.

Herrick JR. 2019. Assisted reproductive technologies for endangered species conservation: developing sophisticated protocols with limited access to animals with unique reproductive mechanisms. Biol. Reprod. 100:1158-1170.

Hummitzsch K, Hatzirodos N, Irving-Rodgers HF, Hartanti MD, Perry VEA, Anderson RA, Rodgers RJ. 2019. Morphometric analyses and gene expression related to germ cells, gonadal ridge epithelial-like cells and granulosa cells during devel- 
opment of the bovine fetal ovary. PLoS One 14:e0214130.

Hummitzsch K, Irving-Rodgers HF, Hatzirodos N, Bonner W, Sabatier L, Reinhardt DP, Sado Y, Ninomiya Y, Wilhelm D, Rodgers RJ. 2013. A new model of development of the mammalian ovary and follicles. PLoS ONE 8:e55578.

Hyttel P, Pessôa LVdeF, Secher JBM, Dittlau KS, Freude K, Hall VJ, Fair T, Assey RJ, Laurincik J, Callesen H, Greve T, Stroebech LB. 2019. Oocytes, embryos and pluripotent stem cells from a biomedical perspective. Anim. Reprod. 16:508-523.

Ivshina M, Lasko P, Richter JD. 2014. Cytoplasmic polyadenylation element binding proteins in development, health, and disease. Annu. Rev. Cell Dev. Biol. 30:393-415.

Jeseta M, Petr J, Krejcová T, Chmelíková E, Jílek F. 2008. In vitro ageing of pig oocytes: effects of the histone deacetylase inhibitor trichostatin A. Zygote 16:145-152.

Jin YX, Zhao MH, Zheng Z, Kwon JS, Lee SK, Cui XS, Kim NH. 2014. Histone deacetylase inhibitor trichostatin A affects porcine oocyte maturation in vitro. Reprod. Fertil. Dev. 26: 806-816.

Jones ASK and Shikanov A. 2019. Follicle development as an orchestrated signaling network in a 3D organoid. J. Biol. Eng. 13:2.

Kim J, Singh AK, Takata Y, Lin K, Shen J, Lu Y, Kerenyi MA, Orkin SH, Chen T. 2015. LSD1 is essential for oocyte meiotic progression by regulating CDC25B expression in mice. Nat. Commun. 6:10116.

Kuge $\mathrm{H}$ and Inoue A. 1992. Maturation of Xenopus laevis oocyte by progesterone requires poly(A) tail elongation of mRNA. Exp. Cell. Res. 202:52-58.

Li J, Zhou W, Wang Y, Niu C. 2018. The dual role of cGMP in oocyte maturation of zebrafish. Biochem. Biophys. Res. Commun. 499:998-1003.

Maddox AS, Azoury J, Dumont J. 2012. Polar body cytokinesis. Cytoskeleton (Hoboken) 69:855-868.

Mao L, Lou H, Lou Y, Wang N, Jin F. 2014. Behaviour of cytoplasmic organelles and cytoskeleton during oocyte maturation. Reprod. Biomed. Online. 28:284-299.

Marlow F. 2015. Primordial germ cell specification and migration. F1000Res. 4:F1000 Faculty Rev-1462.

Masui Y and Markert CL. 1971. Cytoplasmic control of nuclear behavior during meiotic maturation of frog oocytes. J. Exp. Zool. 177:129-145.

Matoba S, O'Hara L, Carter F, Kelly AK, Fair T, Rizos D, Lonergan P. 2012. The association between metabolic parameters and oocyte quality early and late postpartum in Holstein dairy cows. J. Dairy Sci. 95:1257-1266.

McNatty KP, Smith P, Hudson NL, Heath DA, Tisdall DJ, O WS, Braw-Tal R. 2019. Development of the sheep ovary during fetal and early neonatal life and the effect of fecundity genes. J. Reprod. Fertil. Suppl. 49:123-135.

Moncrieff L, Mozdziak P, Jeseta M, Machatkova M, Kranc W, Kempisty B. 2019. Ovarian follicular cells - living in the shadow of stemness cellular competence. Med. J. Cell Biol. 7: 134-140.

Oh HI, Lee SH, Lee S, Lee ST, Lee E, Park CK. 2015. Role of Gol- gi apparatus on regulation of Sec61 $\beta$, COPG2 and epidermal growth factor during oocyte maturation. Reprod. Dev. Biol. 39:37-41.

Pan B and Li J. 2019. The art of oocyte meiotic arrest regulation. Reprod. Biol. Endocrinol. 17:8.

Paulini F, Silva RC, Rôlo JL, Lucci CM. 2014. Ultrastructural changes in oocytes during folliculogenesis in domestic mammals. J. Ovarian Res. 7:102.

Piqué M, López JM, Foissac S, Guigó R, Méndez R. 2008. A combinatorial code for CPE-mediated translational control. Cell 132:434-448.

Pirino G, Wescott MP, Donovan PJ. 2009. Protein kinase A regulates resumption of meiosis by phosphorylation of Cdc25B in mammalian oocytes. Cell Cycle 8:665-670.

Poirier M, Tesfaye D, Hailay T, Salilew-Wondim D, Gebremedhn S, Rings F, Neuhoff C, Schellander K, Hoelker M. 2020. Metabolism-associated genome-wide epigenetic changes in bovine oocytes during early lactation. Sci. Rep. 10:2345.

Pryce JE, Royal MD, Garnsworthy PC, Mao IL. 2004. Fertility in the high-producing dairy cow. Livest. Prod. Sci. 86:125-135.

Racedo SE, Wrenzycki C, Lepikhov K, Salamone D, Walter J, Niemann H. 2009. Epigenetic modifications and related mRNA expression during bovine oocyte in vitro maturation. Reprod. Fertil. Dev. 21:738-748.

Reader KL, Stanton JL, Juengel JL. 2017. The role of oocyte organelles in determining developmental competence. Biology (Basel) 6:E35.

Reyes JM and Ross PJ. 2016. Cytoplasmic polyadenylation in mammalian oocyte maturation. Wiley Interdiscip. Rev. RNA 7:71-89.

Richards JS, Ren YA, Candelaria N, Adams JE, Rajkovic A. 2018. Ovarian follicular theca cell recruitment, differentiation, and impact on fertility: 2017 update. Endocr. Rev. 39:1-20.

Robert A, Hookway C, Gelfand VI. 2016. Intermediate filament dynamics: What we can see now and why it matters. Bioessays 38:232-243.

Roeles J and Tsiavaliaris G. 2019. Actin-microtubule interplay coordinates spindle assembly in human oocytes. Nat. Commun. 10:4651.

Saadeldin IM, Elsayed A, Kim SJ, Moon JH, Lee BC. 2015. A spatial model showing differences between juxtacrine and paracrine mutual oocyte-granulosa cells interactions. Indian J. Exp. Biol. 53:75-81.

Saadeldin IM, Koo OJ, Kang JT, Kwon DK, Park SJ, Kim SJ, Moon JH, Oh HJ, Jang G, Lee BC. 2012. Paradoxical effects of kisspeptin: it enhances oocyte in vitro maturation but has an adverse impact on hatched blastocysts during in vitro culture. Reprod. Fertil. Dev. 24:656-668.

Sendžikaitė G and Kelsey G. 2019. The role and mechanisms of DNA methylation in the oocyte. Essays Biochem. 63:691705.

Sha QQ, Dai XX, Dang Y, Tang F, Liu J, Zhang YL, Fan HY. 2017. A MAPK cascade couples maternal mRNA translation and degradation to meiotic cell cycle progression in mouse oocytes. Development 144:452-463. 
Sheets MD, Fox CA, Dowdle ME, Blaser SI, Chung A, Park S. 2017. Controlling the messenger: regulated translation of maternal mRNAs in Xenopus laevis development. Adv. Exp. Med. Biol. 953:49-82.

Solc P, Schultz RM, Motlik J. 2010. Prophase I arrest and progression to metaphase I in mouse oocytes: comparison of resumption of meiosis and recovery from G2-arrest in somatic cells. Mol. Hum. Reprod. 16:654-664.

Sorensen RA and Wassarman PM. 1976. Relationship between growth and meiotic maturation of the mouse oocyte. Dev. Biol. 50:531-536.

Stelzer Y, Shivalila CS, Soldner F, Markoulaki S, Jaenisch R. 2015. Tracing dynamic changes of DNA methylation at single-cell resolution. Cell 163:218-229.

Stewart KR, Veselovska L, Kelsey G. 2016. Establishment and functions of DNA methylation in the germline. Epigenomics 8:1399-1413.

Stewart KR, Veselovska L, Kim J, Huang J, Saadeh H, Tomizawa S, Smallwood SA, Chen T, Kelsey G. 2015. Dynamic changes in histone modifications precede de novo DNA methylation in oocytes. Genes Dev. 29:2449-2462.

Sun QY and Schatten H. 2006. Regulation of dynamic events by microfilaments during oocyte maturation and fertilization. Reproduction 131:193-205.

Takagi Y, Talbot NC, Rexroad CE Jr, Pursel VG. 1997. Identification of pig primordial germ cells by immunocytochemistry and lectin binding. Mol. Reprod. Dev. 46:567-580.

Tang LS, Wang Q, Xiong B, Hou Y, Zhang YZ, Sun QY, Wang SY. 2007. Dynamic changes in histone acetylation during sheep oocyte maturation. J. Reprod. Dev. 53:555-561.

Taweechaipaisankul A, Jin JX, Lee S, Kim GA, Suh YH, Ahn MS, Park SJ, Lee BY, Lee BC. 2019. Improved early development of porcine cloned embryos by treatment with quisinostat, a potent histone deacetylase inhibitor. J. Reprod. Dev. 65:103112.

Terenzio M, Koley S, Samra N, Rishal I, Zhao Q, Sahoo PK, Urisman A, Marvaldi L, Oses-Prieto JA, Forester C, Gomes
C, Kalinski AL, Di Pizio A, Doron-Mandel E, Perry RB, Koppel I, Twiss JL, Burlingame AL, Fainzilber M. 2018. Locally translated mTOR controls axonal local translation in nerve injury. Science 359:1416-1421.

Tetkova A, Jansova D, Susor A. 2019. Spatio-temporal expression of ANK2 promotes cytokinesis in oocytes. Sci. Rep. 9: 13121.

Viveiros MM and Fuente RDL. 2019. Regulation of mammalian oocyte maturation. In: Leung PCK and Adashi EY (Eds.), The Ovary. Academic Press, London, pp. 165-180.

von Baer KE and O'Malley CD. 1956. On the genesis of the ovum of mammals and of man. Isis 47:117-153.

Wang Q, Wang CM, Ai JS, Xiong B, Yin S, Hou Y, Chen DY, Schatten H, Sun QY. 2006. Histone phosphorylation and pericentromeric histone modifications in oocyte meiosis. Cell cycle 5:1974-1982.

Wang QL, Zhao MH, Jin YX, Kim NH, Cui XS. 2013. Gonadotropins improve porcine oocyte maturation and embryo development through regulation of maternal gene expression. J. Emb. Trans. 28:361-371.

Watson AJ. 2007. Oocyte cytoplasmic maturation: a key mediator of oocyte and embryo developmental competence. J. Anim. Sci. 85(13 Suppl):E1-E3.

Xu M, Qian J, Si L, Qu X, Li J. 2019. The effect of epigenetic changes on the extrusion of the first polar body in pig oocytes during in vitro maturation. Cell. Reprogram. 21:129140.

Yang J, Zhang Y, Xu X, Li J, Yuan F, Bo S, Qiao J, Xia G, Su Y, Zhang M. 2019. Transforming growth factor- $\beta$ is involved in maintaining oocyte meiotic arrest by promoting natriuretic peptide type $\mathrm{C}$ expression in mouse granulosa cells. Cell Death Dis. 10:558.

Young JM and McNeilly AS. 2010. Theca: the forgotten cell of the ovarian follicle. Reproduction 140:489-504.

Zakrzewski W, Dobrzyński M, Szymonowicz M, Rybak Z. 2019. Stem cells: past, present, and future. Stem Cell Res. Ther. 10:68. 